\title{
Mechanization of Pruning, Canopy Management, and Harvest in Winegrape Vineyards
}

\section{S. Kaan Kurtural ${ }^{1 *}$ and Matthew W. Fidelibus ${ }^{1}$ \\ Cite this article: \\ Kurtural SK and Fidelibus MW. 2021. Mechanization of pruning, canopy management, and harvest in winegrape vineyards. Catalyst 5:29-44.}

${ }^{1}$ Department of Viticulture and Enology, University of California Davis, 1 Shields Avenue, Davis, CA 95616.

${ }^{*}$ Corresponding author (skkurtural@ucdavis.edu)

Acknowledgments: The authors would like to acknowledge the American Vineyard Foundation, Bronco Wine Company, West Coast Grape Farming Incorporated, Constellation Brands US, V-Mech LLC, and Oxbo Inc. for their financial and in-kind support during the execution of the all the referenced trials that were conducted in California that made this review possible. Technical expertise and assistance of Gregory T. Berg, Saul Arriola, Tom Valdero, Jose Valdez, Brian Franzia, Carol Franzia, Michael Blaine, Daniel Bosch, Geoffrey Dervishian, Dave B. Terry, Jose Luis Huizar, Joseph Geller, Lydia Nida, Runze Yu, Michael Cook, Clinton Nelson, and especially Professor Emeritus Robert Wample, have been invaluable in conducting these works. The corresponding author is indebted to Mr. Freddie T. Franzia of Bronco Wine Co. for enabling vineyard mechanization research in California.

Manuscript submitted Dec 2020, revised Feb 2021, March 2021, accepted April 2021

This is an open access article distributed under the CC BY license (https://creativecommons.org/ licenses/by/4.0/).

By downloading and/or receiving this article, you agree to the Disclaimer of Warranties and Liability. The full statement of the Disclaimers is available at https://www.asevcatalyst.org/content/ proprietary-rights-notice-catalyst. If you do not agree to the Disclaimers, do not download and/or accept this article. doi: 10.5344/catalyst.2021.20011

\section{Summary}

Aim: In winegrape production, pruning, canopy management, and harvest are essential practices that are increasingly being done by machines. How well these practices are executed can substantially affect fruit yield and quality. Mechanization offers timeliness, uniformity, and cost benefits, but most methods available to date are nonselective and optimal execution requires careful attention to vineyard design, management, and machine settings. This review provides information to help growers make the best use of machines for these tasks.

\section{Key Themes:}

- Vineyard design considerations

- Winter pruning

- Canopy management

- Harvesting

Impact and Significance: The need to manage large vineyards in a contracting labor market is achievable with mechanization. This review summarizes the best practices in consideration of vineyard design, as well as operation of machines for optimal productivity for the winegrape grower. This review also provides information to help growers effectively incorporate the machines in their vineyards for consistent and economical production of winegrapes including pruning, shootthinning, fruit-zone leaf removal, crop load management, and mechanical harvest.

Key words: canopy management, crop removal, fruit-zone leaf removal, mechanization, pruning, shoot-thinning, viticultural practice

\section{Overview}

Many winegrape cultural practices, including pruning, canopy management, and harvest, are laborious and time sensitive. However, California and many other winegrape production regions are facing rising wage costs and labor shortages. ${ }^{1,2}$ Ongoing labor shortages were heightened in 2020 because of the novel coronavirus pandemic. ${ }^{3}$ Thus, there is an increasing need to farm with fewer people, in a more cost-effective and timely manner. ${ }^{4}$

The most laborious vineyard tasks are dormant pruning, canopy management, and harvesting, ${ }^{5}$ and mechanization for these methods has received considerable attention from academics, equipment manufacturers, and growers. ${ }^{6}$ As growers adapted to mechanical harvest ${ }^{7}$ and pruning, they searched for other methods to mechanize other cultural operations such as shoot ${ }^{6}$ and fruit-zone leaf removal, ${ }^{8,9,10}$ berry thinning, ${ }^{11}$ and shoot positioning. ${ }^{12}$ Machinery was developed and commercialized by researchers at the University of Arkansas ${ }^{13,14}$ and commercialized by partners for these practices. Adoption of such machinery is increasing with economic necessity and as growers develop the knowledge and experience necessary to use these tools effectively.

Current vineyard mechanization equipment reduces the need for seasonal manual labor for certain tasks, but does not eliminate it. ${ }^{15}$ The degree to which manual labor can be reduced depends on the growing region (coastal versus inland), grapevine cultivar (upright versus downright growth habit), and the 
number of cultural practices (harvest only or pruning and other practices) the grower is able to mechanize. Furthermore, because vineyard mechanization relies heavily on information-based decision-making, growers need fewer, but more highly skilled, personnel for optimal vineyard management. This review will provide information to help growers effectively incorporate machines in their vineyards for consistent and economical production of winegrapes.

\section{Key Themes}

Vineyard design considerations. Preparation for vineyard mechanization ideally starts before grapevines are planted. Some key elements to consider, as in traditionally farmed vineyards, are soil uniformity within blocks, ${ }^{16}$ blocking by cultivar or irrigation need, ${ }^{17}$ drainage, slope, and consistency of grade.

Ideally, mechanization will optimize investment per unit land area and production consistency. This is best achieved by optimizing uniformity within blocks for soil properties such as fertility and soil water drainage, which are helpful in this regard. ${ }^{18}$ Sites with inconsistent grade with irregular knolls should be avoided because of safety concerns and variability. Variable grades within a vineyard will often increase vine-to-vine ${ }^{19}$ variability because of changes in soil properties. ${ }^{4,19,20}$ Vineyard management in mechanized vineyards is further simplified when vineyard blocks are planted to the same rootstock and cultivar. Well-drained soils are important in mecha- nized vineyards because equipment access and deployment are hindered in waterlogged vineyards after heavy precipitation. Most equipment will operate safely on slopes up to $7 \%{ }^{5,21}$

Factors that need consideration when designing a vineyard for mechanization are available equipment, adequate inter- and in-row spacing, headland size, trellising, irrigation, and cultivar selection. Growers must pay attention to certain details to maximize success in future years when designing a vineyard for mechanization. Desired properties are listed in Table 1.

Long, straight rows that are adequately spaced are essential. Long rows increase operating efficiency, while straight rows minimize vine injury and damage to line posts (Figure 1). Adequate interrow spacing is desired to allow for lateral adjustment of equipment during operations. Growers need to carefully consider which implements and power units are needed and provide adequate space for their safe operation. Because most growers have full-size equipment, row spacing in mechanized vineyards needs to adhere to the 2.73 to $3.35 \mathrm{~m}$ distance for single canopy systems and 3.66 to $4.27 \mathrm{~m}$ for double, vertically divided, canopy systems.

Uniform vine spacing is essential for mechanized vineyards. Currently available equipment is compatible with both single and double curtain trellis systems, and uniform vine spacing permits the use of this equipment. Unlike manual operations where a laborer can adjust density of buds depending on grapevine in-row

\begin{tabular}{|c|c|c|}
\hline Attribute & Desired condition & Corrective action \\
\hline Plant uniformity & High & $\begin{array}{l}\text { Divide block into homogenous units } \\
\text { Adjust irrigation zones }\end{array}$ \\
\hline Plant condition & Straight and healthy & Retrain if needed \\
\hline Trunks & Established, straight, and taut & Retrain \\
\hline Cordons & Established, straight, and taut & Retrain \\
\hline Bearing spur density & Adequate $\sim 21$ to $42 \mathrm{spurs} / \mathrm{m}$ & Retrain \\
\hline Pruning mass $(\mathrm{kg} / \mathrm{m})$ & $\begin{array}{l}\text { Moderate to high } \\
\text { Up to } 0.5 \mathrm{~kg} / \mathrm{m} \text { (cool/cold climate) } \\
\text { Up to } 1 \mathrm{~kg} / \mathrm{m} \text { (warm to hot climate) }\end{array}$ & Adjust by pruning \\
\hline Training & Uniform & Retrain \\
\hline Cultivar market potential & High & Top-work \\
\hline Bearing habit & Amenable to cordon training and spur pruning & Top-work \\
\hline Fruit maturation & Adequate for season length at vineyard location & $\begin{array}{l}\text { Control early season irrigation } \\
\text { Control leaf layer numbers }\end{array}$ \\
\hline Trellis and training system & Single high-wire, vertical shoot-positioned, or quadrilateral & Convert trellis \\
\hline End assembly & Stout and able to carry load and force & Repair or reinstall \\
\hline Line posts & Tall, galvanized steel, beveled at least $2500 \mathrm{~mm}$ & Reinstall \\
\hline Cordon wire & Uniform height, at least $2.304 \mathrm{~mm}$ & Replace \\
\hline Row spacing & Wide enough to accommodate gondola at $2895 \mathrm{~mm}$ & Modify \\
\hline Irrigation supply & Match at least $80 \%$ of crop evapotranspiration demand & Modify \\
\hline Irrigation line & At least $550 \mathrm{~mm}$ above vineyard floor & Modify \\
\hline
\end{tabular}


spacing, equipment is insensitive to these irregularities. Variability in grapevine spacing may also lead to variability in harvest dates, ${ }^{22}$ crop load, ${ }^{23}$ and canopy density, ${ }^{24}$ thereby negatively affecting fruit composition at the farm gate. ${ }^{2,20}$ Grapevine spacing in the middle to upper range is most desirable in mechanized vineyards. In-row spacing of 1.83 to $2.13 \mathrm{~m}$ has proven adequate under most conditions. ${ }^{4,9,21}$

In manually tended vineyards, headland width of 7.6 $\mathrm{m}$ to $9.2 \mathrm{~m}$ have been adequate. However, because longer equipment with a wider turning radius is used in mecha-

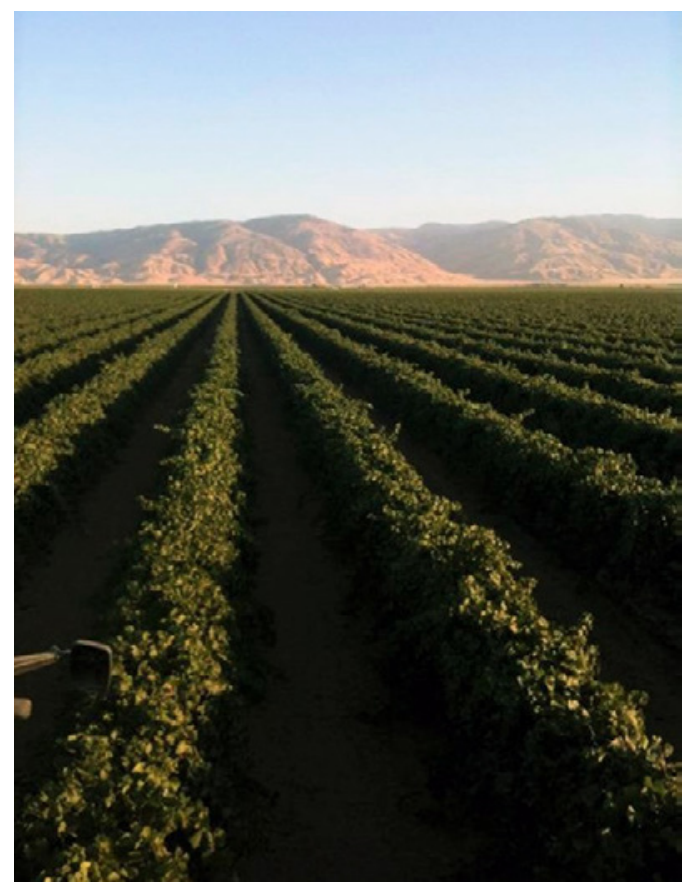

Figure 1 Long, continuous $3.2 \mathrm{~km}$ rows in a Pinot gris vineyard in Kern County, California. Long rows are preferred to minimize the number of turns for the continuous operation of mechanical equipment.

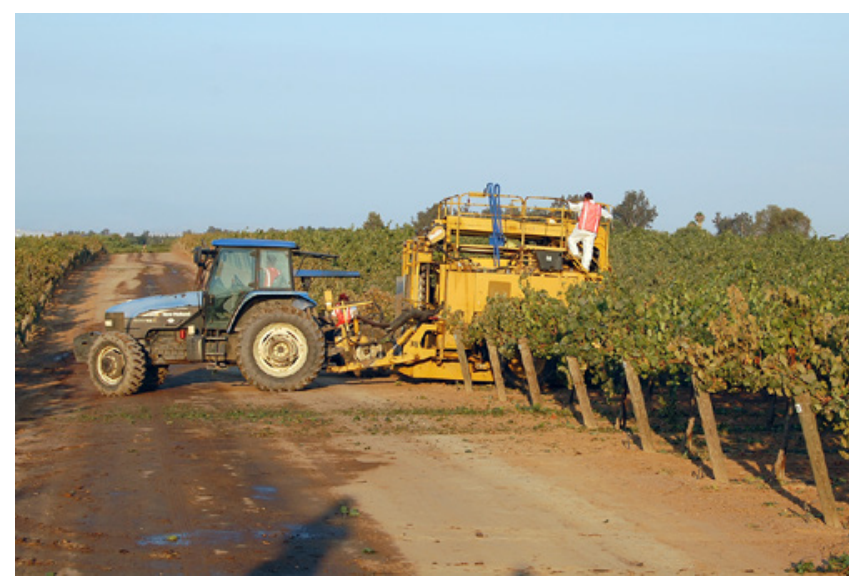

Figure 2 Proper spacing between alleyways will ensure long-machines can turn into rows easily. nized vineyards (Figure 2, Supplemental Video 1), headlands having a minimum width of $10.7 \mathrm{~m}$ are needed. In adjacent vineyard blocks that share a headland and have rows that are in line with each other, wider alleyways further facilitate equipment movement between blocks, minimize turns, and align implements with rows, thereby maximizing efficiency.

Although most trellises can be mechanized to some extent, growers seeking a high level of mechanization in their vineyards should consider using the trellis that is most amenable to mechanization. The currently available vineyard mechanization equipment works best with single curtain trellis systems; however, quadrilateral and vertically separated trellises can also be managed with mechanization. The adaptability of most common trellis and training types are summarized in Table 2 . In selecting a trellis system, consider the growth habit of the cultivar, ${ }^{21,22}$ the climate, and potential yields of the vineyard. Mechanized vineyards need stout, highquality trellis materials with strong tie-back assemblies to withstand crop weight without sagging and to bear the torque and force applied by equipment. Row lengths up to two miles are common in the San Joaquin Valley of California, so high-quality materials are needed to set up the trellis and secure it. Commonly, a support-line post is installed at every vine with a cordon wire gauge of 2.3 to $2.6 \mathrm{~mm}$ (American Wire Gauge [AWG] 10 to 11) to carry the weight of the crop and withstand cultural operations. Support-line posts are made of galvanized steel with beveled edges to deflect wind, facilitate harvest, and increase durability and longevity (Figure 3). The end posts are constructed from steel and have a narrow profile and spaded ends. Desired dimensions for these materials are presented in Table 3.

For single high-wire trellis systems, the grapevine trunks are trained against the line post $\mathrm{t}^{4}$ (Figure 4A). The line posts should not extend $>5 \mathrm{~cm}$ above the cordon wire so that they will not obstruct mechanical pruners. As the grapevine's spurs grow, ${ }^{1}$ they will extend above the line posts and can be pruned without the pruning blades impacting the posts. Similarly, used in vertical shoot-positioned trellis systems (Figure 4B), the cordon wire is positioned at a height compatible with the implement to aid mechanization.

For quadrilateral systems, the grapevine is trained with the line post as well. ${ }^{21}$ In this system, a $0.6 \mathrm{~m}$-wide cross arm is secured to the line post at 1.4 to $1.6 \mathrm{~m}$ above the vineyard floor and two bilateral cordons are trained on the cordon wires (Figure 5A and 5B)

The design of irrigation systems in mechanized vineyards should incorporate the needs of the rootstock and 
cultivar combination to meet crop evapotranspiration demand. ${ }^{17,25}$ Drip irrigation lines should be placed high enough to avoid interfering with collector plates of mechanical harvesters. It is advised that inline emitters are used instead of button types, which can be broken off by machinery. Usually, a line height of 55 to $60 \mathrm{~cm}$ above the vineyard floor is required. The risers and gate valves of irrigation systems need to be constructed out of flexible tubing to minimize the damage from impact of harvesters or other implements (Figure 6).

More vineyard operations can be mechanized if cultivars grown can be trained to have straight trunks and lateral cordons. Cultivars having fruitful basal buds are more easily adapted to mechanization using currently

Table 2 Adaptability of common trellis types to vineyard mechanization found in major production areas of California. VSP, vertical shoot-positioned.

\begin{tabular}{|c|c|c|c|c|c|}
\hline & California sprawl & VSP & Quadrilateral & Single high-wire & Head-trained \\
\hline Prepruning & $+++^{a}$ & ++++ & +++ & ++++ & - \\
\hline Final pruning & ++ & ++ & +++ & ++++ & - \\
\hline Shoot-thinning & ++ & ++ & +++ & ++++ & - \\
\hline Leaf removal & ++ & ++++ & +++ & ++++ & ++ \\
\hline Crop adjustment & ++ & ++ & - & ++++ & + \\
\hline Trunk suckering & +++ & +++ & +++ & ++++ & - \\
\hline Harvest & +++ & ++++ & ++++ & ++++ & - \\
\hline
\end{tabular}

a-, not conducted; +, not very adaptable; ++, somewhat adaptable; +++, adaptable; ++++, greatly adaptable.

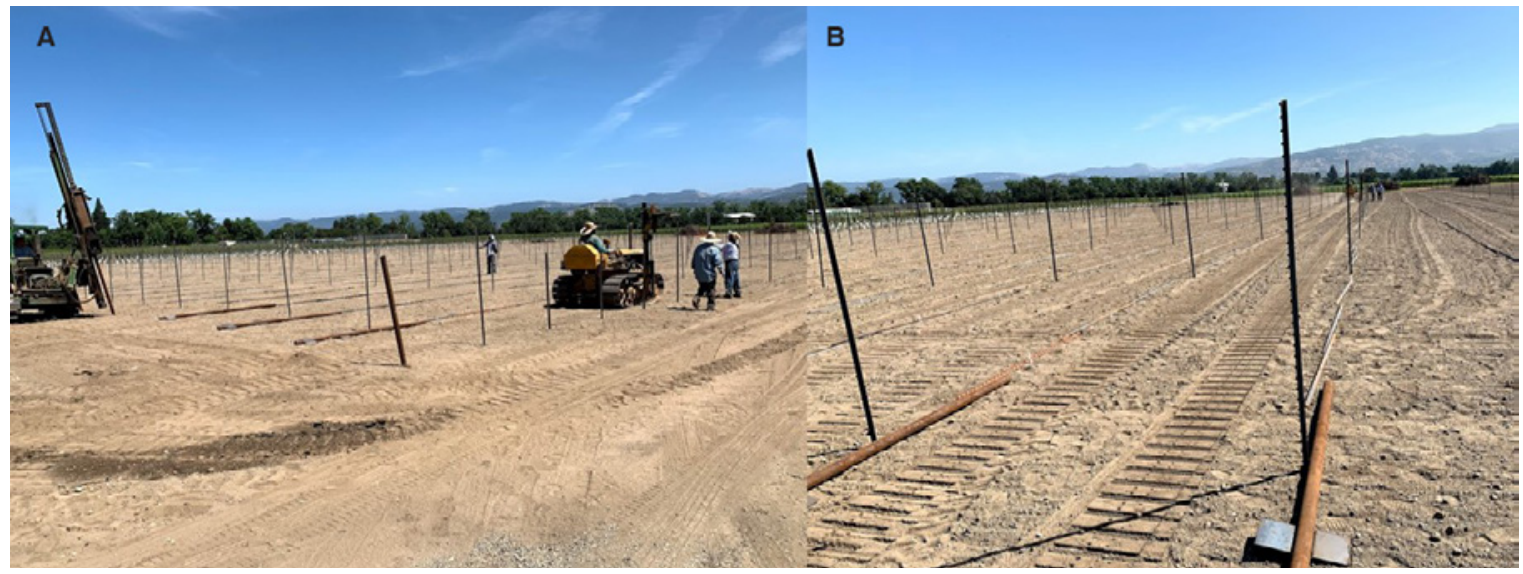

Figure 3 (A) High quality steel end posts and line posts are needed to ensure that the load of fruit and the torque from machines can be handled. (B) Narrow profile steel end posts with spaded ends are preferred in mechanically managed vineyard installation.

Table 3 Desired dimensions for end posts and wires used in mechanically managed vineyards. VSP, vertical shoot-positioned.

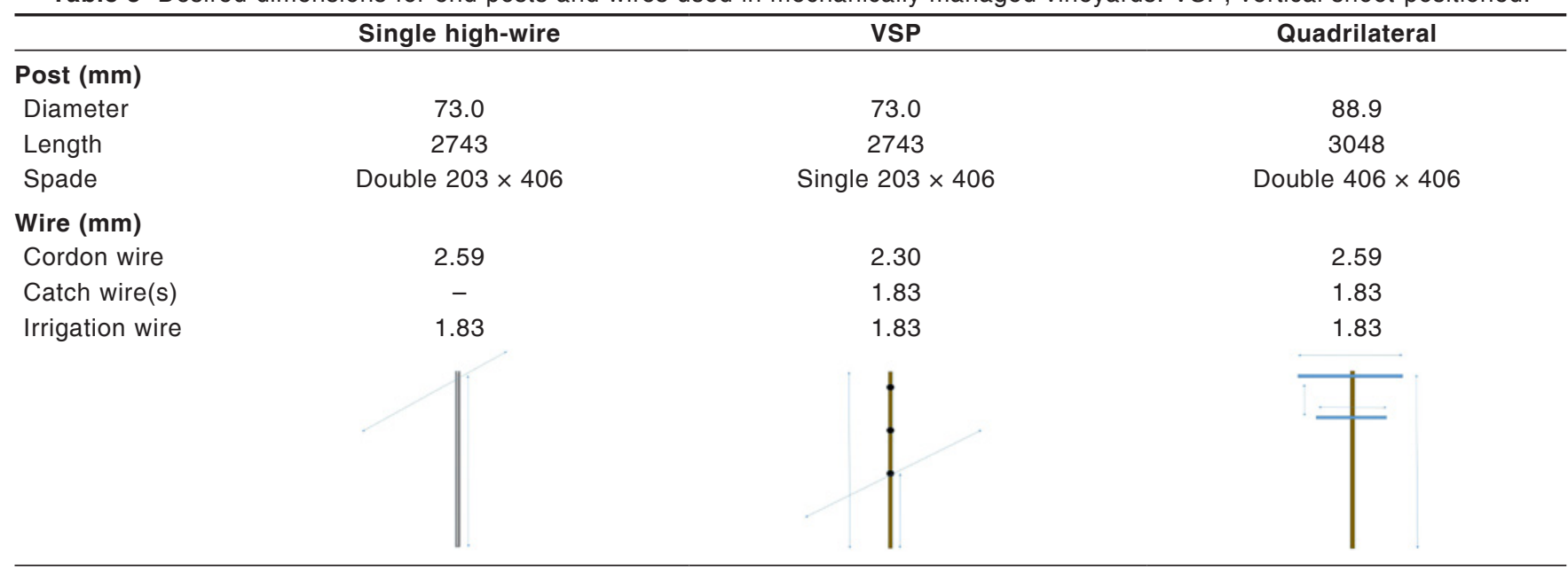


available equipment. Cultivars requiring adjustments to spur length, to retain sufficient numbers of fruitful buds, are less amenable to mechanized pruning. ${ }^{6,26}$

Winter pruning. Dormant pruning is one of the most labor-intensive practices in vineyards. ${ }^{1,8}$ It is estimated that $\sim 80 \%$ of all labor operations costs in vineyards can be attributed to the combination of pruning and harvesting practices. ${ }^{27}$ For mechanized vineyards, dormant pruning is best depicted along a continuum of two extremes. ${ }^{12}$ On one extreme is hand pruning that produces precisely controlled numbers of short spurs and buds. On the other extreme is minimal pruning to retain numerous longer spurs with less precision.

Mechanical pruning types. Minimal pruning. The reasoning behind minimal pruning is that the development of high numbers of clusters would be balanced by the early growth of numerous vegetative shoots. ${ }^{11}$ The result is production of high yields composed of many very small clusters and berries. However, minimal pruning has all but been abandoned because of the inability to control trunk diseases, the proliferation of dead wood, reduction in primary bud cold-hardiness, and less than ideal fruit composition, which limits marketability. ${ }^{28}$

Mechanical box-pruning. As the name suggests, the grapevine's bearing spurs are pruned from the top, bottom, and sides to resemble a box. ${ }^{2,4,17,21}$ Box pruning is the mechanized technique that most closely resembles hand pruning, although box pruning is not selective, leaving all the nodes within the perimeter of the cuts (Figure 7, Supplemental Video 1). Box height and the width can be manipulated by the pruning-machine operator. A prepruning pass ${ }^{15}$ may leave a $0.3 \mathrm{~m}$ wide by $0.4 \mathrm{~m}$ high box (recommended in frost prone areas (Figure 8), whereas a precision pruning pass may leave a 0.10 to $0.15 \mathrm{~m}$ high $\times 0.10$ to $0.15 \mathrm{~m}$ wide box. The following approaches are generally used when implementing mechanical box-pruning:

Prepruning, hand pruning, and thinning follow-up. Dormant shoots are mechanically prepruned to a $0.30 \mathrm{~cm}$

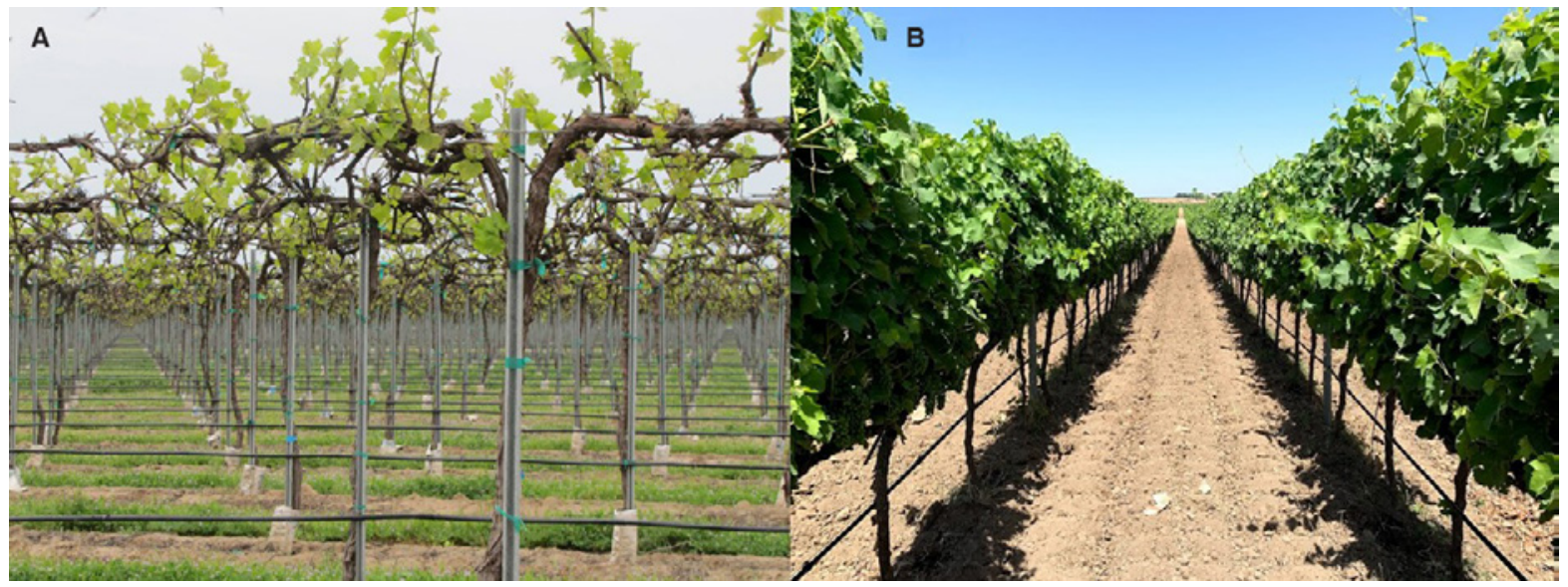

Figure 4 (A) Single high-wire trellis with beveled line post and the cordon wire, and (B) vertically shoot-positioned trellis with three grapevine panels with line stakes.

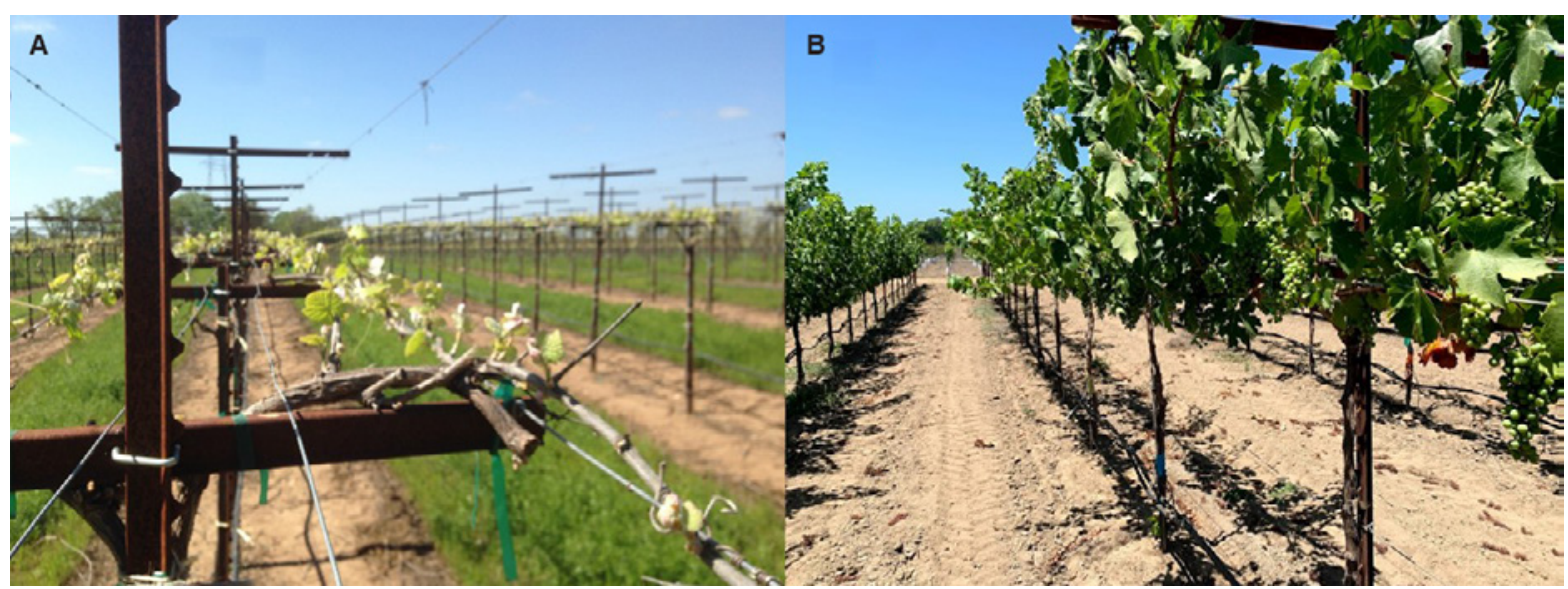

Figure 5 (A) Quadrilateral trellis as cordons are being trained and (B) at full canopy with the sprawling shoots caught by the catch-wires at the t-top. 
to $0.40 \mathrm{~m}$ tall $\times 0.10 \mathrm{~m}$ wide box retaining 120 to $200 \%$ of the desired number of buds. After budbreak and the danger of frost has passed, the desired shoot density is achieved by manual pruning and shoot-thinning. ${ }^{15}$

Prepruning, mechanical shoot thinning follow-up. Dormant canes are mechanically prepruned to a $0.1 \mathrm{~m}$ wide $\times$ 0.3 to $0.4 \mathrm{~m}$ high box, retaining 120 to $200 \%$ predicted bud load. After budbreak and the danger of frost has passed, the desired shoot density is achieved by shoot-thinning.

Mechanical box-pruning, mechanical shoot thinning follow-up. Canes are mechanically box-pruned to a 0.10 to $0.15 \mathrm{~m}$ tall $\times 0.10 \mathrm{~m}$ wide box. After budbreak and the danger of frost has passed, the desired shoot density is achieved by mechanical shoot-thinning (described later).

Early mechanical pruners were adaptations of existing equipment such as vertically mounted hedger bars, which would be used to clean row ends or do summer trimming. As the industry demand for mechanical hedgers increased, the hedger bars became more elaborate

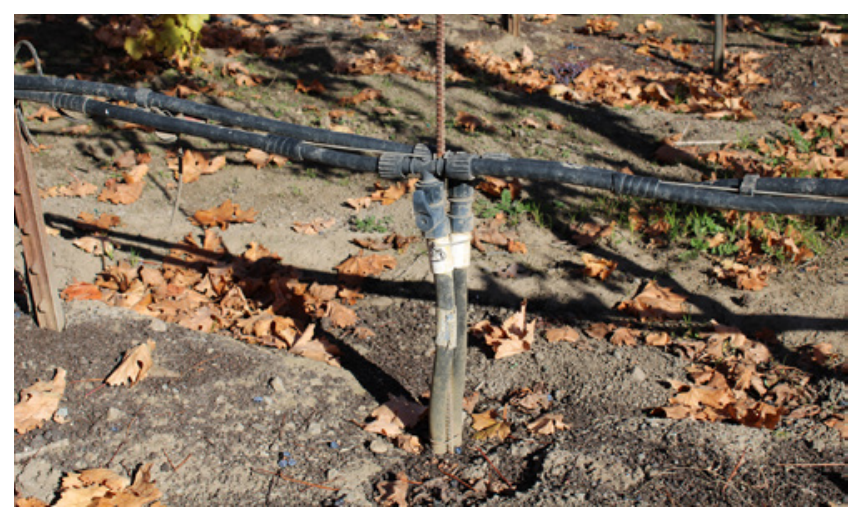

Figure 6 Properly installed irrigation gate valve, fertilizer injection port at the correct height of $55 \mathrm{~cm}$ above vineyard floor.

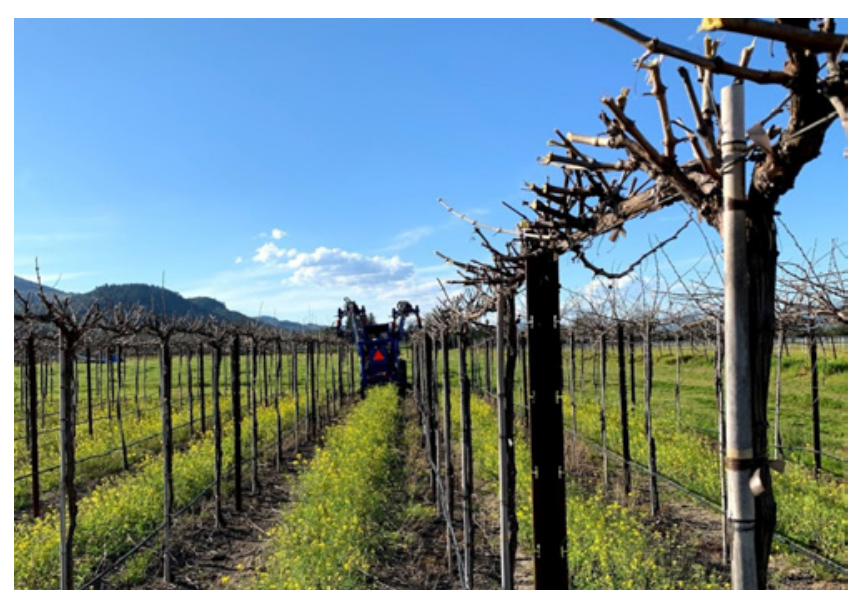

Figure 7 Mechanical box-pruning at a single-high wire Cabernet Sauvignon vineyard during the dormant season. and articulated. Hedger bars make the main vertical plane of cut in combination-type pruners.

Hedger bar pruners. Hedger bar pruners (Figure 9), when mounted singly, have a single plane of cut and low penetration into the dormant canopy. They have an efficient cutting mechanism consisting of two opposing serrated cutting surfaces, which operate in opposing directions of the plane of travel, matching the ground speed of the tractor. They have low hydraulic flow requirements and can easily be operated with a hydraulic pump having a $38 \mathrm{~L} / \mathrm{min}$ flow rate. Because they have low penetration into the canopy, they are mostly used in minimal pruning applications in the dormant season, for summer pruning, or as part of combination pruners.

Rotary and drum pruners. Rotary and drum pruners (Figure 10), whether mounted singly or in stacks, have greater penetration into the dormant canopy than do hedger bars. Depending on the cutting surface used

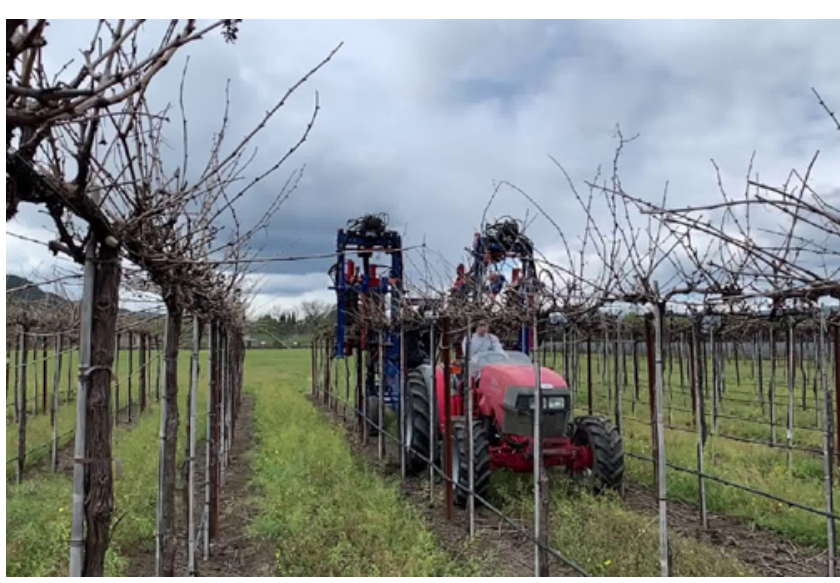

Figure 8 Mechanical prepruning at a Cabernet Sauvignon vineyard in Napa County, California.

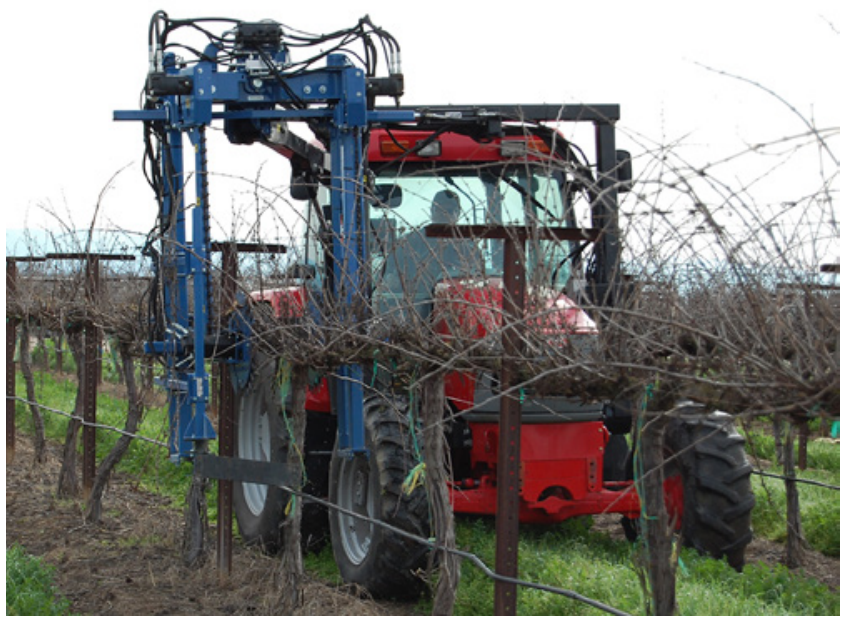

Figure 9 Hedger bars removing the sprawl and undergrowth of a sprawling canopy in Madera County, California. 
(rotating drums or saws), they can be used either for summer pruning or for setting height of the bearing spurs during dormant pruning. When mounted singly and operating on a single row, rotary pruners have a low hydraulic flow requirement and can be operated with a $38 \mathrm{~L} / \mathrm{min}$ flow rate hydraulic pump.

Combination and sprawl pruners. Combination pruners make multiple plane cuts by combining rotary pruners and several hedger bars (Figure 11, Supplemental Video 1). For example, a combination of rotary pruners can be positioned horizontally and vertically to define the height and width of the bearing surface. In combination with hedger bars, they will prune away the canes that sprawled out of the canopy or above the permitted canopy height. These pruners usually require a toolbar to be installed, with an independently operating power unit to deliver the hydraulic flow to drive these implements. There are units that can be mounted into mechanical harvester frames or trailers with operator stations (Figure 12). Rotary pruners are the most common and efficient pruners, capable of pruning 1 ha in $4.5 \mathrm{hr}$, saving significant labor costs compared ${ }^{6,15}$ to hand pruning.

Effects on yield, fruit composition. Pruning is a rough regulator of yield because of the unpredictable nature of fruitful buds breaking from noncount positions..$^{15}$ There-

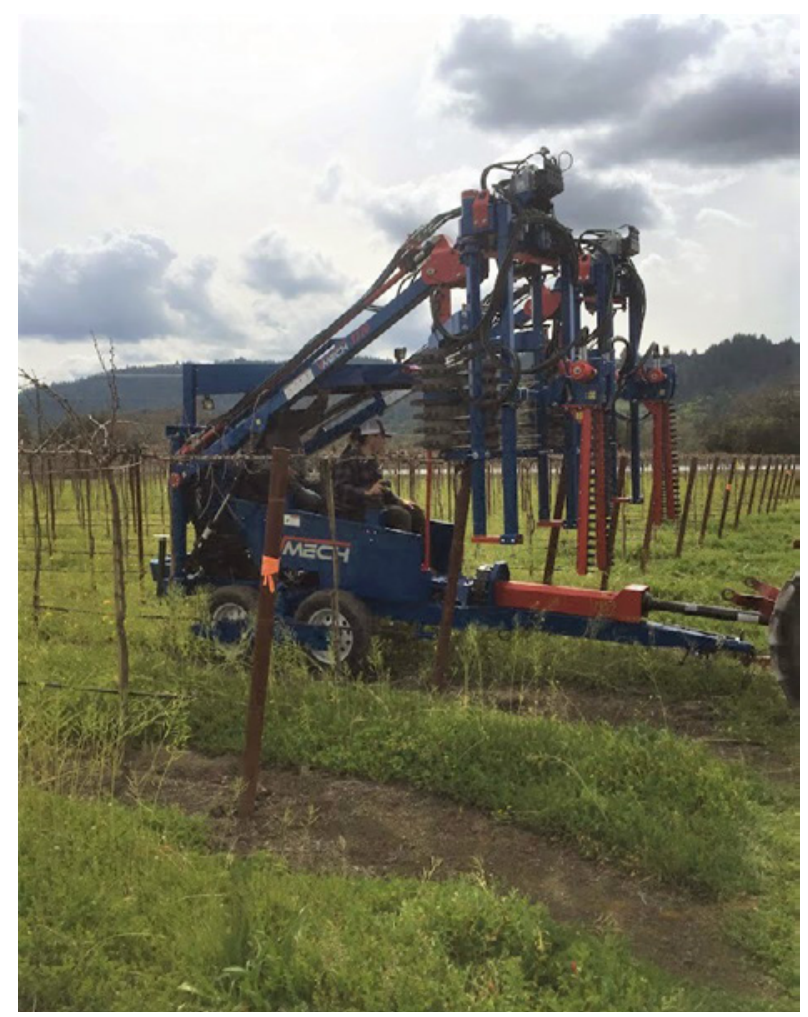

Figure 10 A rotary and drum mechanical pruner used in mechanical box pruning with hedger bar cutters on the side removing the sprawl. fore, other techniques are needed to control yield. Generally, mechanically pruned vineyards are higher yielding ${ }^{29}$ than manually pruned vineyards by $\sim 30 \%$ in the initial eight years. ${ }^{8}$ However, as the vineyard balances and the fruit zone becomes less fruitful because of mutual shading, ${ }^{22}$ the yield levels off, and there are negligible differences between manually and mechanically pruned vineyards. ${ }^{4}$

There is agreement in literature that berry total soluble solids accumulation in mechanically pruned vineyards is slower than in manually pruned vineyards. ${ }^{30,31,32}$ This is attributed to a combination of higher crop level with shorter shoots, and more leaf layers shading the clusters. ${ }^{10}$ In regions with longer growing seasons this is usually not a concern. However, in regions with short growing seasons and early killing frosts, growers

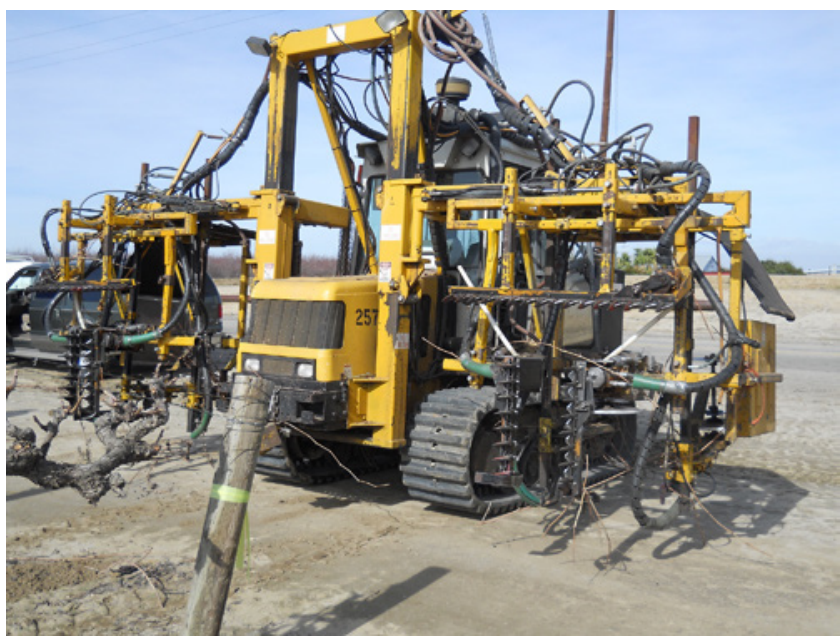

Figure 11 A combination mechanical pruner that is used in California sprawl type trellis in the San Joaquin Valley of California.

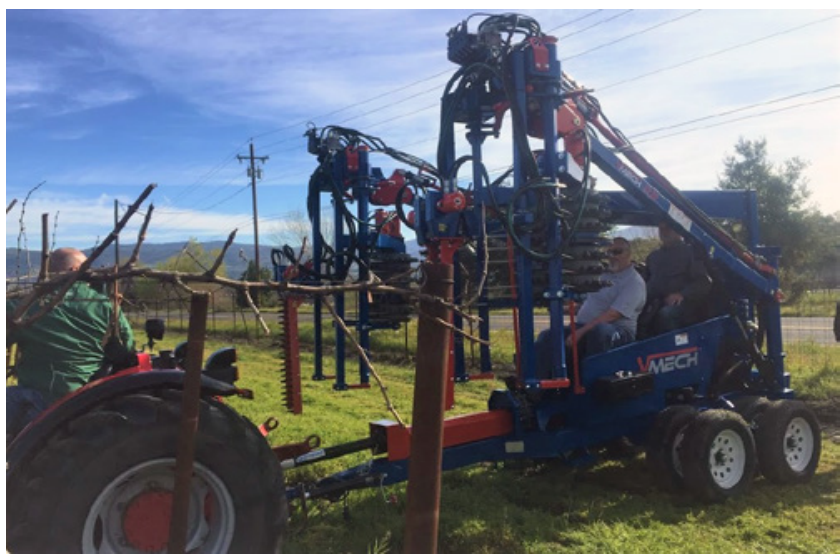

Figure 12 A multipurpose carrier frame with combination mechanical pruners installed that can prune two rows at a time in a Chardonnay vineyard in the central coast of California. 
should shoot thin. ${ }^{33}$ Furthermore, mechanically pruned vineyards produce smaller berries ${ }^{8,34}$ than do manually pruned vineyards. Smaller berries are purported to have a skin-to-pulp ${ }^{6}$ ratio preferred by winemakers because it leads to higher polyphenolic concentrations in wine. Recent research revealed that mechanically pruned vineyards have more exposed leaf area relative to total leaf area compared to hand-pruned grapevines, ${ }^{35}$ enabling the flavonoid pathway to be upregulated. ${ }^{20}$

Research in interior and coastal California $1,8,27,36,37$ has shown that using one of the pruning management strategies described above would save between 60 to $80 \%$ of labor operation costs per acre compared to manual pruning alone. ${ }^{1,8,27,37}$ In a study comparing traditional Guyot cane pruning, manual spur pruning, and complete mechanization in Madera, CA, researchers found that converting traditionally farmed systems will save $80 \%$ of labor operations cost without any differences in berry primary and secondary metabolites. A detailed breakdown of labor operation costs in using this approach, including mechanical pruning, is provided in Table $4 .{ }^{1}$

Canopy management mechanization. Manufacturers developed mechanized implements to complete all canopy management requirements for the growing season. Below are some mechanized canopy management practices that have verifiable physiological effects with economic benefit.

Shoot-thinning. Mechanical shoot thinners use soft silicone "finger-like" protrusions on a rotating drum to brush the cordon (Figure 13A) and a rotating shoot

\begin{tabular}{|c|c|c|c|c|c|}
\hline & $\$ / \mathrm{hr}$ & hr/ha & \$/ha & $\begin{array}{c}\text { Gross revenue } \\
(\$ / \mathrm{ha})^{\mathrm{a}}\end{array}$ & $\begin{array}{c}\text { Net farm } \\
\text { income }(\$ / \mathrm{ha})^{\mathrm{b}}\end{array}$ \\
\hline \multicolumn{6}{|l|}{2013} \\
\hline \multicolumn{6}{|l|}{$\mathrm{CPc}$} \\
\hline Hand pruning labor & $\$ 9.50$ & 79 & 750.5 & & \\
\hline Cane-tying & $\$ 9.50$ & 3.9 & 37.05 & & \\
\hline Benefit rate ${ }^{d}$ & $33 \%$ & & 282.42 & & \\
\hline Total & & & 1070.42 & 8982.08 & 7911.67 \\
\hline \multicolumn{6}{|l|}{ HP } \\
\hline Training labor & $\$ 9.50$ & 72.1 & 684.95 & & \\
\hline Training follow-up & $\$ 9.50$ & 2.9 & 27.55 & & \\
\hline Benefit rate & $33 \%$ & & 235.13 & & \\
\hline Total & & & 947.63 & 8978.45 & 8030.82 \\
\hline \multicolumn{6}{|l|}{ SHMP } \\
\hline Training labor & $\$ 9.50$ & 72.1 & 684.95 & & \\
\hline Training follow up & $\$ 9.50$ & 2.9 & 27.55 & & \\
\hline Benefit rate & $33 \%$ & & 235.13 & & \\
\hline Total & & & 947.63 & 6945.64 & 5998.01 \\
\hline \multicolumn{6}{|l|}{2014} \\
\hline \multicolumn{6}{|l|}{$\mathrm{CP}$} \\
\hline Hand pruning labor & 10.50 & 79 & 829.50 & & \\
\hline Cane-tying & 10.50 & 3 & 31.5 & & \\
\hline Benefit rate & $33 \%$ & & 284.13 & & \\
\hline Total & & & 1145.14 & 4471.32 & 3326.18 \\
\hline \multicolumn{6}{|l|}{ HP } \\
\hline Hand pruning labor & 10.50 & 71 & 745.5 & & \\
\hline Hand pruning follow-up & 10.50 & 3 & 31.5 & & \\
\hline Benefit rate & $33 \%$ & & 256.41 & & \\
\hline Total & & & 1033.41 & 4033.14 & 2999.73 \\
\hline \multicolumn{6}{|l|}{ SHMP } \\
\hline Mechanical pruning labor & 13.50 & 4.56 & 61.56 & & \\
\hline Equipment maintenance labor & 13.50 & 0.59 & 7.96 & & \\
\hline Benefit rate & $33 \%$ & & 22.94 & & \\
\hline Pruning fuel & $\begin{array}{c}4.56 \mathrm{hr} / \mathrm{ha} \times 3.785 \mathrm{~L} / \mathrm{h} \\
\times \$ 1.06 / \mathrm{L}\end{array}$ & & 18.29 & & \\
\hline Total & & & 110.75 & 5256.78 & 5146.03 \\
\hline
\end{tabular}


thinner with soft paddles that strike the canopy at a known pace (Figure 13B). Growers need to assess the canopy density (number of count shoots, noncount shoots per foot of row) before calibrating and using the mechanical shoot thinner. The mechanical shoot thinner is not selective, that is to say it does not remove specific shoots, but rather strikes the canopy at a known frequency that can be adjusted (Supplemental Video 2). The shoot thinner is ideal for regions that are prone to frost where prepruning passes have retained more nodes than necessary or for cultivars that are prone to over cropping. Growers are advised to apply mechanical shoot-thinning around the time of cluster elongation. The mechanical shoot thinners have four planes of motion and will require an external power unit to provide enough hydraulic flow to power the implements.

Mechanical shoot-thinning reduces shoot density ${ }^{6,8,35}$ and is an efficient crop-thinning method. However, its effect may be temporary unless a mild water deficit is imposed to inhibit lateral and secondary shoot growth. ${ }^{8}$ It further assists in establishing fruiting positions in the following year. In Table 5, the effects of shoot-thinning on leaf area, yield, and cumulative yield reduction to Colombard grapevines grown on Freedom rootstock in Fresno County, CA, are shown. Mechanical shoot-thinning applied early reduced leaf layers and increased the exposure of clusters to moderate levels of sunlight, thereby improving berry phenolic content of red wine grape varieties. ${ }^{6}$ In considering whether or not to shoot thin, the grower has to consider the potential loss of income from reduced yield and the possibility of increased income from better fruit composition. The application cost of mechanical shoot-thinning is $\$ 197 / \mathrm{ha}^{27,37}$ compared to $\$ 1482 /$ ha for manual shoot-thinning. ${ }^{27}$

Trunk suckering. During the spring growth flush, shoots may develop from latent buds on the trunk. Traditionally, these unwanted shoots were removed manually ${ }^{37}$ with crews. However, as the height of canopies

Table 4 (continued) Labor operations costs (\$/ha), gross revenue, and net income per hectare $(\$ /$ ha) of Merlot grapevine on Freedom rootstock during transitioning to mechanical pruning in central San Joaquin Valley of California. (c) American Society for Horticultural Science 2019 HortTechnology 29:128-139.

\begin{tabular}{|c|c|c|c|c|c|}
\hline & $\$ / \mathrm{hr}$ & $\mathrm{hr} / \mathrm{ha}$ & \$/ha & $\begin{array}{c}\text { Gross revenue } \\
(\$ / \mathrm{ha})^{\mathrm{a}}\end{array}$ & $\begin{array}{c}\text { Net farm } \\
\text { income }(\$ / \mathrm{ha})^{\mathrm{b}}\end{array}$ \\
\hline \multicolumn{6}{|l|}{2015} \\
\hline \multicolumn{6}{|l|}{$\mathrm{CP}$} \\
\hline Hand pruning labor & 10.50 & 79 & 829.5 & & \\
\hline Cane-tying & 10.50 & 1.5 & 15.75 & & \\
\hline Benefit rate & $33 \%$ & & 278.93 & & \\
\hline Total & & & 1124.18 & 3030.38 & 1990.29 \\
\hline \multicolumn{6}{|l|}{ HP } \\
\hline Hand pruning labor & 10.50 & 51 & 535.5 & & \\
\hline Hand pruning follow-up & 10.50 & 2.9 & 30.5 & & \\
\hline Benefit rate & $33 \%$ & & 186.78 & & \\
\hline Total & & & 752.78 & 3019.20 & 2443.42 \\
\hline \multicolumn{6}{|l|}{ SHMP } \\
\hline Mechanical pruning labor & $\$ 15.00$ & 4.56 & 68.40 & & \\
\hline Equipment maintenance labor & $\$ 15.00$ & 0.59 & 8.8 & & \\
\hline Benefit rate & $33 \%$ & & 25.48 & & \\
\hline Pruning fuel & $\begin{array}{c}4.56 \mathrm{hr} / \mathrm{ha} \times 3.785 \mathrm{~L} / \mathrm{h} \\
\times \$ 1.06 / \mathrm{L}\end{array}$ & & 18.29 & & \\
\hline Total & & & 120.97 & 4584.37 & 4463.39 \\
\hline \multicolumn{6}{|l|}{ Cumulative } \\
\hline CP & & & 3331 & 16,483 & 13,152 \\
\hline HP & & & 3031 & 16,207 & 13,176 \\
\hline SHMP & & & 1143 & 16,786 & 15,643 \\
\hline \multicolumn{6}{|c|}{$\begin{array}{l}\text { a Merlot price/ton is based on average price for Crush District } 13 \text { in } 2013,2014 \text {, and } 2015 \text { according to California Grape Crush Report. }{ }^{47,48,49} \\
\text { bet farm income }(\$ / \text { ha) calculated gross farm receipts }(\$ / \mathrm{ha}) \text { - labor operations costs }(\$ / \mathrm{ha}) \text {. } \\
\text { b } \mathrm{CP}=\text { trained to a } 96 \mathrm{~cm} \text { tall trunk, with four, } 8 \text {-node canes trained at } 110 \mathrm{~cm} \text { and an additional two, } 8 \text {-node canes that were trained a } \\
137 \mathrm{~cm} \text {, in opposing directions, HP = California Sprawl system with a cordon wire at } 137 \mathrm{~cm} \text { above vineyard floor and two parallel catch } \\
\text { wires at } 167 \mathrm{~cm} \text { above the vineyard floor, and spur-pruned to retain } 22 \text { spurs with two nodes each per vine, SHMP = single high-wire } \\
\text { sprawling system cordon wire was established } 167 \mathrm{~cm} \text { above the vineyard floor and a bilateral cordon was established to generate an } \\
\text { SHMP that was mechanically box-pruned at a } 10 \mathrm{~cm} \text { spur height, and mechanical pruner's speed is } 0.8 \mathrm{~km} / \mathrm{hr} \text {. } \\
\text { dBenefit rate: A percentage of wages paid to state or federal government or healthcare providers to comply with regulations. }\end{array}$} \\
\hline
\end{tabular}


increased with modern trellis systems such as single high-wire or high quadrilateral, the necessity to do this practice by machine has increased. ${ }^{15,27}$ The machines that can do these tasks are now mounted to the front of the tractor (Supplemental Video 3 ) and strike the trunk of the grapevine with silicone fingers affixed to a rotating drum. The trunk sucker machines use the hydraulic flow of a common vineyard tractor with a flow rate of $38 \mathrm{~L} /$ min and can remove suckers on both sides of the row. In a study conducted in Napa County, CA, the cost to manually sucker trunks was $\$ 1493 /$ ha. $^{27}$ When done by the machine, the cost was reduced to $\$ 154 /$ ha, providing almost an order of magnitude in labor operations cost savings. ${ }^{37}$

Leaf removal. Various implements can remove leaves mechanically. The goals of fruit-zone leaf removal can include limiting crop level by reducing the number of berries that set, ${ }^{38}$ improving cluster exposure to sunlight ${ }^{36}$ depending on timing, and improving air flow to reduce fungal infections, ${ }^{39}$ but the outcome must balance crop level with exposed leaf area. ${ }^{36}$ Generally, fruit-zone leaf removal equipment operates on the principle that leaves are lighter than clusters and can either be sucked into a baffle and cut off (Figure 14A) or rolled over an expanded aluminum drum (Figure 14B) that screens out flowers and clusters but "plucks" away leaves (Supplemental Video 4). There are also implements that force leaves off petioles with short bursts of air.
Timing. Balancing crop level and exposed leaf area requires precise fruit-zone leaf removal timing. If conducted prebloom, ${ }^{40}$ the response of the grapevine is to reduce the number of berries set, ${ }^{41}$ providing greater exposure with reduced yield. If conducted postbloom, ${ }^{23}$ the result for the grapevine is increased solar radiation and temperature in the fruit zone. The cost to apply mechanical fruit-zone leaf removal is $\$ 247 /$ ha compared to $\$ 1500 /$ ha when conducted manually in coastal California. ${ }^{27}$

Effects on yield, fruit composition. Depending on timing and the climate in which the fruit is grown, fruit-zone leaf removal might not affect yield ${ }^{9,10}$ or it may reduce yield. In warm regions, fruit-zone leaf removal often has a minimal effect on yield, but an improvement on leaf area to fruit ratio should be expected ${ }^{36}$ as a result of removing excessive leaf layers, which shade the cluster in the fruiting zone. ${ }^{10}$ By removing $\sim 20 \%$ of leaf area, a more balanced grapevine was achieved, ${ }^{20}$ however, the biggest beneficial effect of fruit-zone leaf removal is increased berry flavonoid content. ${ }^{36}$ As depicted in Table 6 , even in warm-climate viticulture regions, anthocyanin accumulation in the berry can be increased by early season fruit-zone leaf removal. ${ }^{10}$

Crop load management using vineyard mechanization. Crop load is the ratio of fruit to pruning weight, and a commonly recommended desirable range is 5 to $12^{8,42}$ depending on the cultivar and location of the vineyard.

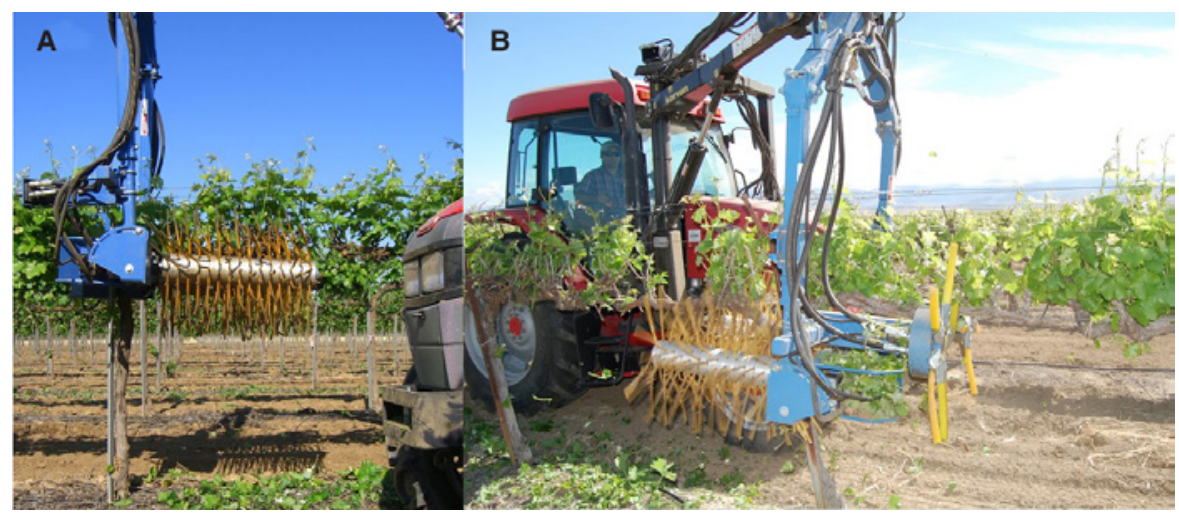

Figure 13 A shoot removal implement with a cordon brush with silicone fingers on $(\mathbf{A})$ a rotating drum and $(\mathbf{B})$ the shoot removal paddle in the front of the rotating drum.

Table 5 Leaf area reduction of Colombard grapevine grown on Freedom rootstock under mechanical shoot-thinning to 21 shoots $/ \mathrm{m}$ of row and cumulative reductions in yield and gross farm income in three consecutive seasons in Crush District 13 of California.

\begin{tabular}{|c|c|c|c|c|c|c|c|c|}
\hline & \multicolumn{3}{|c|}{ Leaf area at bloom $\left(\mathrm{m}^{2}\right)$} & \multicolumn{3}{|c|}{ Yield reduction } & \multirow{2}{*}{$\begin{array}{l}\text { Cumulative } \\
\text { reduction ( } \mathrm{t} / \mathrm{ha} \text { ) }\end{array}$} & \multirow{2}{*}{$\begin{array}{c}\text { Cumulative } \\
\text { income } \\
\text { reduction(\$/ha) }\end{array}$} \\
\hline & Primary & Lateral & Total & 2009 & 2010 & 2011 & & \\
\hline Control & $6.1 \mathrm{a}^{\mathrm{a}}$ & $2.3 \mathrm{a}$ & $8.4 \mathrm{a}$ & - & - & - & - & - \\
\hline 21 shoots $/ \mathrm{m}$ & $4.0 \mathrm{~b}$ & $2.1 \mathrm{a}$ & $6.1 \mathrm{~b}$ & $22 \%$ & $14 \%$ & $28 \%$ & 34.07 & $\$ 10,222$ \\
\hline $\operatorname{Pr}>F^{\mathrm{b}}$ & 0.0001 & $N^{c}$ & 0.0001 & & & & & \\
\hline
\end{tabular}

${ }^{a}$ Columns with different letters are significantly different at $p<0.05$ according to Tukey's honest significant difference test.

${ }^{\mathrm{b}} \mathrm{Pr}>F$, probability of attaining an $\mathrm{F}$ test according to one-way analysis of variance.

${ }^{\mathrm{b} N S}$, not significantly different at $p<0.05$. 
The whole-season approach to using machines to regulate crop load could use all or some of the implements (e.g., pruner, shoot thinner, leaf remover) described previously. Possible management options are described below and differ according to grapevine growth habit.

Grapevines that have a downward growth habit such as Merlot, ${ }^{1}$ Zinfandel, ${ }^{6,10}$ and Syrah ${ }^{22}$ are not as amenable to whole season crop load management using mechanization as are vines with an upward growth habit such as Cabernet Sauvignon, ${ }^{4}$ Cabernet franc, or Chardonnay. The issue has to do with increased sunlight received from postmechanical pruning, which results in vegetative compensation by the grapevine. ${ }^{22,28}$ In the case of downward growth habit grapevines, the canopy is quickly repopulated, thereby negating any effects of higher amounts of solar radiation received, resulting in poor berry development. In cultivars such as Syrah, ${ }^{23}$ Merlot, ${ }^{1}$ and Zinfandel, ${ }^{30}$ mechanical box-pruning followed by mechanical shoot-thinning resulted in less than ideal yield-to-pruning weight ratio and poor anthocyanin accumulation. ${ }^{23} \mathrm{Crop}$ load management in procumbent grapevines may be limited to a prepruning pass with a mechanical pruner and hand shoot-removal follow up and mechanical harvest.

Grapevines with an upward growth habit are more amenable to whole-season crop load management with mechanization. All the steps of canopy management can be performed mechanically and reliably because upward growth habit grapevines respond more beneficially to increased solar radiation exposure to growing shoots, and ideal yield-to-pruning weight ratios can be achieved.

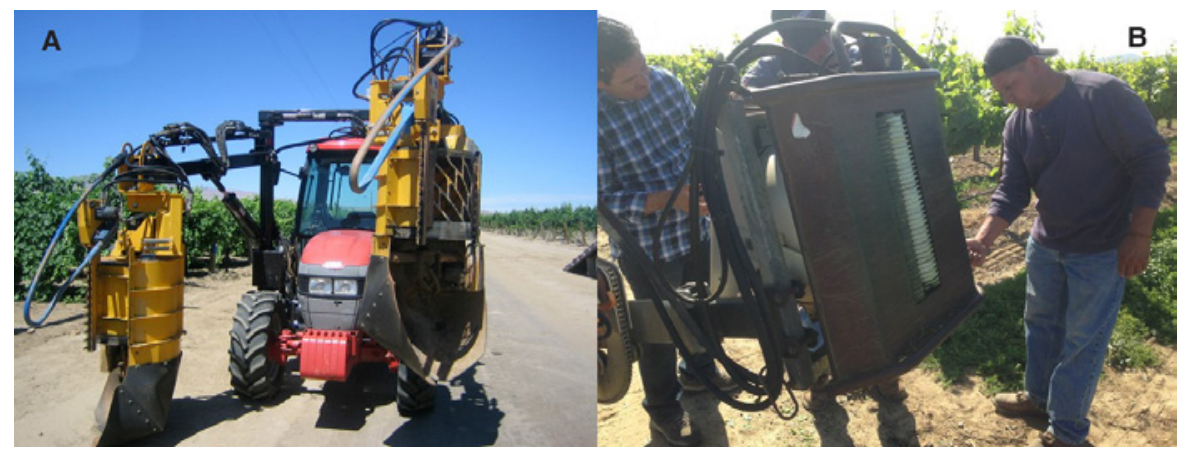

Figure 14 Common fruit-zone leaf removal implements used in vineyards with $(\mathbf{A})$ a suck-and-cut type and (B) a roll-over type of fruit-zone leaf removal machine with a $50 \mathrm{~cm}$ baffle exposed.

Table 6 Effect of mechanical removal timing and fractions of crop evapotranspiration replacement on labor operations cost of canopy management and cost of producing total skin anthocyanins per hectare in northern California. (C) 2015 American Society for Enology and Viticulture, AJEV 66:266-278.

\begin{tabular}{|c|c|c|c|c|}
\hline & $\begin{array}{l}\text { Leaf removal cost } \\
(\$ / \mathrm{ha})\end{array}$ & $\begin{array}{c}\text { Irrigation water cost } \\
(\$ / \mathrm{ha})\end{array}$ & $\begin{array}{c}\text { Total anthocyanin } \\
\text { produced (g/ha) }\end{array}$ & $\begin{array}{c}\text { Unit anthocyanin } \\
\text { production cost }(\$ / g)\end{array}$ \\
\hline \multicolumn{5}{|l|}{ Year I } \\
\hline Control + SDI & 0 & 950 & $1086 c^{b}$ & $1.56 \mathrm{a}$ \\
\hline Control + RDIc & 0 & 827 & $1718 b$ & $0.92 \mathrm{bc}$ \\
\hline Prebloom + SDI & 30 & 950 & 1976 a & $0.87 \mathrm{c}$ \\
\hline Prebloom + RDI & 30 & 827 & 1958 a & $0.82 \mathrm{c}$ \\
\hline Post-fruit set + SDI & 30 & 950 & $1589 \mathrm{~b}$ & $1.09 \mathrm{~b}$ \\
\hline Post-fruit set + RDI & 30 & 827 & $1799 a b$ & $0.89 \mathrm{c}$ \\
\hline $\operatorname{Pr}>F^{\mathrm{d}}$ & & & 0.0001 & 0.0001 \\
\hline \multicolumn{5}{|l|}{ Year II } \\
\hline Control + SDI & 0 & 1235 & $1079 \mathrm{c}$ & $1.84 \mathrm{a}$ \\
\hline Control + RDI & 0 & 1029 & $1261 \mathrm{~b}$ & $1.41 \mathrm{~b}$ \\
\hline Prebloom + SDI & 30 & 1235 & $1657 \mathrm{a}$ & $1.21 \mathrm{c}$ \\
\hline Prebloom + RDI & 30 & 1029 & $1552 \mathrm{a}$ & $1.16 \mathrm{c}$ \\
\hline Post-fruit set + SDI & 30 & 1235 & 1062 c & $1.90 \mathrm{a}$ \\
\hline Post-fruit set + RDI & 30 & 1029 & $1181 \mathrm{~b}$ & $1.63 \mathrm{~b}$ \\
\hline $\operatorname{Pr}>F^{d}$ & & & & 0.0001 \\
\hline
\end{tabular}

aSDI, sustained deficit irrigation applied from bloom to harvest at 0.7 crop evapotranspiration replacement.

bMeans with different letters within the same column are significantly different according to Tukey's honest significant difference test. ${ }^{\mathrm{C}} \mathrm{RDI}$, regulated deficit irrigation applied from bloom to fruit set at 0.7 , fruit set to veraison 0.5 , and veraison to harvest at $0.7 \mathrm{crop}$ evapotranspiration replacement.

${ }^{\mathrm{d}} \mathrm{Pr}>\mathrm{F}$, probability of attaining an $\mathrm{F}$ test according to analysis of variance. 
Crop-thinning. Crop-thinning can be accomplished with mechanization. ${ }^{31}$ Operating a mechanical harvester at a low frequency with some beater bars removed is a simple way to remove a portion of the berries on a vine. In a study conducted in Fresno County, Sauvignon blanc berries were shaken off at BB size ( 3 to $5 \mathrm{~mm}$ ) with beater bars positioned $1 \mathrm{ft}$ below the fruiting zone, at a ground speed of $2.4 \mathrm{kph}$ and $470 \mathrm{RPM}$ (rotations per minute). This reduced yield by $50 \%$, and reduced cluster compactness by $60 \%$ compared to grapevines that were not crop-thinned. The cost to do manual crop-thinning was $\$ 1340 /$ ha for vertically shoot-positioned canopy ${ }^{27}$ in Napa County. To achieve a similar cropping level with a mechanical harvester, the cost was reduced to $\$ 803 / \mathrm{ha}^{2}{ }^{27}$ However, the benefit of this practice has to be managed by the grower for loss of yield versus an improvement in berry composition. ${ }^{36}$

The effectiveness of crop-thinning depends on timing. A rule of thumb is to thin postfruit-set and preveraison. If thinning is done too soon, the grapevine may set more fruit, whereas thinning too late may not affect fruit quality. ${ }^{43,44,45}$ Most studies have shown that the ideal time to thin is when berries are the size of BBs. ${ }^{33,44}$ Mechanical crop-thinning, like shoot-thinning, is nonselective. Particular berries or clusters are not targeted. The grapevine fruit zone is struck or beat with beater bars that detach the BB-sized berries from their rachises. Beating frequency must be adjusted to attain a predetermined production level. Rigorous crop estimation and field sampling should be conducted before implementing berry thinning to ensure appropriate levels of thinning. In the absence of a reliable, nondestructive crop estimation tool, growers need to keep very accurate records of yield.

The grower's aim is to balance crop level with exposed leaf area. ${ }^{31,35}$ The immediate effect in the current season is a reduction in yield, ${ }^{36}$ but an improvement in leaf area-to-fruit weight ratio is also realized because exposed leaf area is kept constant. ${ }^{46}$ Ripening is hastened, especially soluble solids accumulation. ${ }^{6}$ However, reducing the number of berries without affecting leaf area can result in an undesirable increase in berry size, ${ }^{44}$ although the grower can manage this with water deficits. ${ }^{25}$ Generally, a $25 \%$ reduction in number of berries by crop-thinning results in a 15 to $17 \%$ reduction in yield, due to compensatory growth of the remaining berries. ${ }^{31}$

Mechanical grape harvesting. Hand harvesting has some benefits including selectivity (rotten and unripe clusters can be avoided), but it is laborious and limits harvesting to daytime hours when temperatures are higher and can promote premature fermentation. Me- chanical grape harvesting is less selective but requires far fewer people, proceeds much more quickly, and can be done at night. In general, $5 \mathrm{t}$ of fruit can be picked in an hour at night under cooler temperatures, which maintains fruit quality and minimizes premature fermentation. About $90 \%$ of the winegrapes crushed in the United States are mechanically harvested. ${ }^{32}$ If time is of the essence, mechanical harvesting is the best option. The speed of mechanical harvesters gives a grower better control over harvest timing than could be achieved with a hand-picking crew. To optimize mechanical harvesting, the trellis has to be installed correctly with correct vine and row spacing (Tables 1 and 3). Other considerations for growers are logistics, i.e., delivery of large amounts of fruit to the winery and shipping times, and minimizing materials other than grapes (MOG) in the harvested fruit, which will be discussed later.

The current rate for hand harvesting is $\$ 90$ to $\$ 111 / \mathrm{t}$ of winegrapes. Five to six laborers are required to pick 1 t/hr. A study conducted in Fresno, CA, found that labor for harvesting a vineyard that produces on average 17.3 t/ha would cost $\$ 1384$ to $\$ 1729 /$ ha, whereas machine harvesting would cost $\$ 679$ to $\$ 865 / h a{ }^{37}$ This is an $\sim 50 \%$ savings in labor operations costs, and it ensures timely delivery to the winery.

Harvester types. Grape harvesters are either pullbehind, requiring auxiliary power, or self-propelled. Pull-behind harvesters are the most economic choice for growers who already have a large tractor, so pull-behind mechanical harvesters are the most common. Some pullbehind harvesters have hydrostatic drive to assist in hill climbing. They can be fit with either canopy or trunk shaker heads to fit the needs of the grower. The advantages of this type of harvester include safer operations on slopes, lower initial cost, and the ability to select and substitute power units. The disadvantages of this type of harvester are more grapevine and trellis damage due to having an auxiliary power source, higher operation difficulty requiring more laborers, and their tendency to slide into the row if the speed of forward travel is not maintained constant.

Self-propelled harvesters have a larger initial investment requirement than pull-behind harvesters. They have hydrostatic drivetrains and are engine-driven. Advantages of self-propelled harvesters include maneuverability, stability in most situations, ease of operation, and less grapevine and trellis damage. Disadvantages of selfpropelled harvesters include initial high cost, fixed horsepower, and a power unit that is not easily substituted.

Picking head types. Canopy shakers are the most common picking heads. A canopy shaker uses a bow rod head 
(Figure 15B). The picking head in this case compresses the canopy and transfers the force of the picking head to the canopy and trellis to detach the berries or clusters from the vine. The nylon picking rods are $2.54 \mathrm{~cm}$ diam, extruded, and formed into bowed rods. The rods are attached to the picking head with steel or aluminum holders. The following adjustments can be made to a canopy shaker machine bow rod picking head to accommodate a cultivar of trellis height and canopy girth:

- Stroke: 10 to $20 \mathrm{~cm}$

- Rod spacing: 5 to $20 \mathrm{~cm}$

- Rod tension: firm to very firm

- Throat width: best fit (250 to $1000 \mathrm{~mm}$ )

- Revolution speed: 300 to $450 \mathrm{rpm}$

- Forward speed: 1.6 to $5 \mathrm{~km} / \mathrm{hr}$

Trunk shakers are used in winegrape vineyards with small clustered, short pedicel cultivars where transfer of force directly to the vine trunk is desired (Figure 15C). The trunk shaker type of picking head operates by trans- ferring the force of two revolving counterweights to two rails that are moving in the opposite direction of harvester travel. Trunk shaker harvesters are quite heavy and need a large power unit to operate them. The following adjustments can be made to trunk shaker machines to accommodate characteristics of the trellis and the height of grapevines:

- Head tuning: counterweights must be in time

- Pinch pressure: best fit to prevent damage to the graft union

- Pinch spacing: best fit to prevent damage to the graft union

- Height of rails: $>55 \mathrm{~cm}$ if vineyard is drip-irrigated

- Head revolution speed: 120 to $300 \mathrm{rpm}$

- Forward speed: 1.6 to $5 \mathrm{~km} / \mathrm{hr}$

Fruit catching and delivery systems. Once grape berries are picked, they need to be caught and delivered cleanly to a bin. The grape berry catching systems in mechanical harvesters are constructed from Lexan (General Electric)

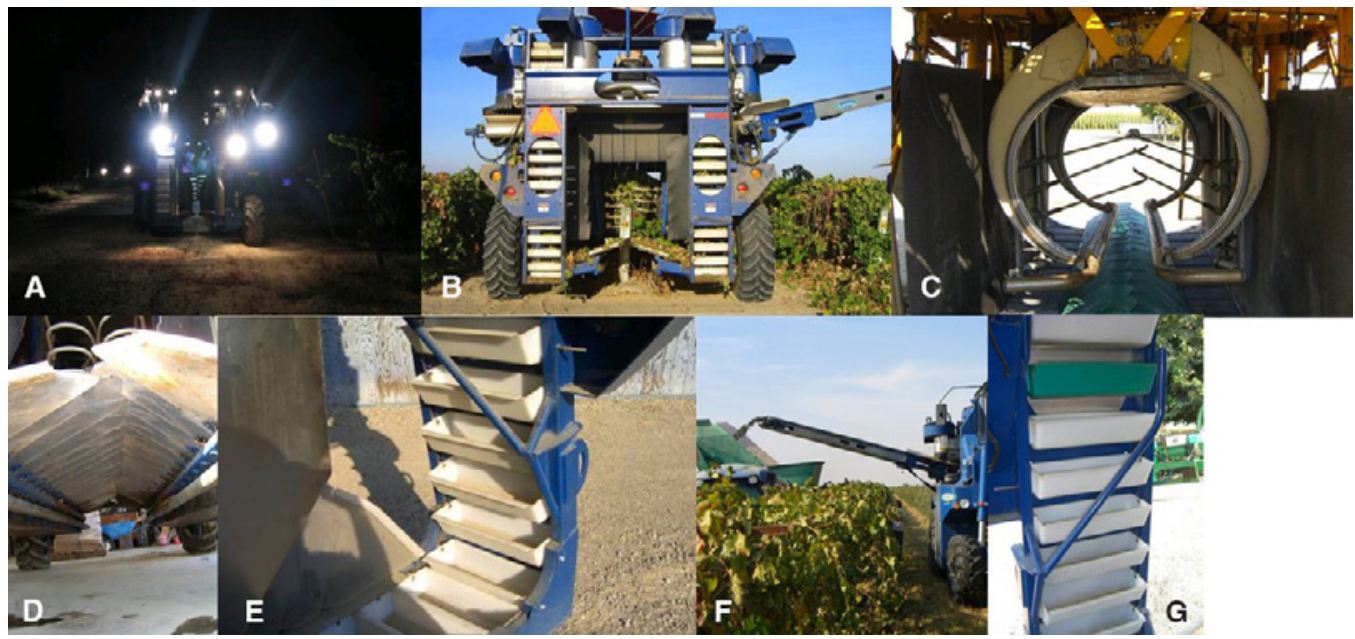

Figure 15 Parts of a mechanical harvester, typically used in California, operating (A) at night, with (B) a canopy shaker head with the bow rods visible, (C) a trunk shaker head with the rails in the bottom above the catcher plates, (D) the catcher plates that go around the trunk and line posts, (E) the conveyor belt with food grade buckets that transports the berries to the top of the harvester to the kicker belt, (F) the over-the-row conveyor used to deliver fruit to receptacle bin in the neighboring row, and $(\mathbf{G})$ passive mechanism for keeping canes and sticks out of the fruit buckets with the slider bar.
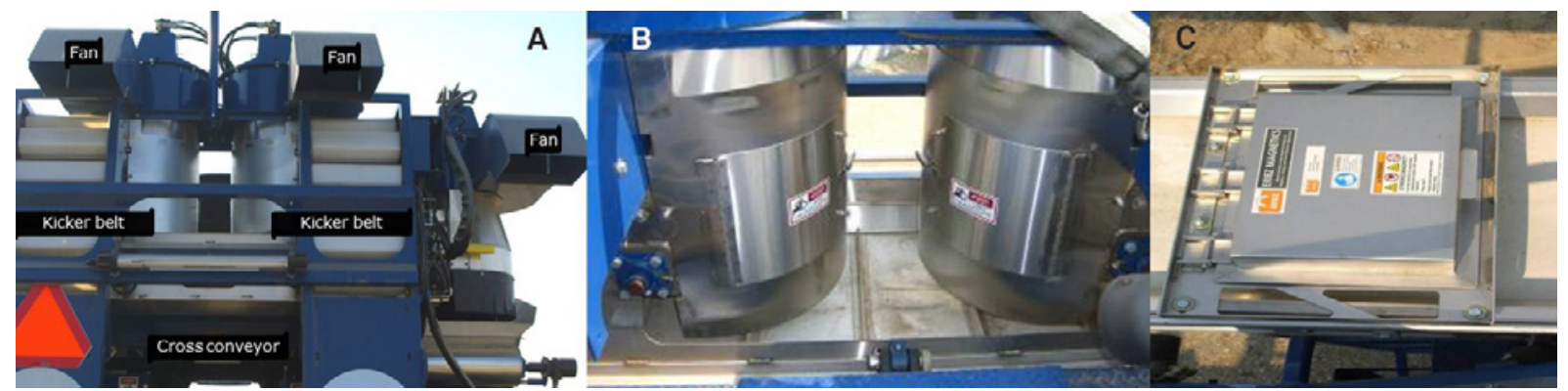

Figure 16 The cleaning system of a typical mechanical harvester indicating the location of (A) the kicker belt and cleaning fans, (B) the kicker belt and the drop cleaning fans, and (C) the ferrous material cleaner on the over-the-row conveyor before fruit is delivered to receptacle bin. 
or nylon and are referred to as "catcher plates." They are designed like flower petals or overlapping leaves (Figure 15D). The plates open and close as needed to pass around vine trunks and trellis line posts. The catcher plates are unidirectional so the operator cannot back up.

Berries on the collector plates are shed into a bucket conveying system (Figure 15E). The system consists of high-impact buckets attached to roller chains that are hydraulically driven. The berries are conveyed to the top of the harvester in an almost static state with no dragging, rolling, or unnecessary dumping. At the top of the harvester, the berries are dumped into an over-the-row conveyor (OTR) system (Figure 15F). The OTR system conveys the berries from the harvester, over the adjacent row, and into a companion gondola or bin trailer. The swing and height of the OTR are adjustable by the operator to fit vineyard conditions.

Fruit cleaning systems. As the canopy is struck by bow rods or shaken by rails, some MOG inevitably fall into the catcher plate stream. MOG may include canes, leaves, trellis parts, and other debris found in the canopy. The allowable levels are relatively low, typically between 2 to $5 \%$. The best way to minimize MOG is to properly set up the vineyard and adjust the harvester settings. However, some MOG is unavoidable, so harvesters are built with active and passive systems that remove MOG. The active MOG removal systems start at the point of transfer between the catcher plate and the bucket conveying system. A rotary MOG deflector removes loose debris such as leaves, canes, and green shoots by knocking them out of the stream, preventing buildup at this point. As the bucket conveying system transfers the fruit to the top of the harvester, a passive MOG cleaning system called a "MOG slider tube" (Figure 15G) guides large canes and sticks out of the buckets. As the berries are transferred from buckets to main kicker belts, the berries are directed inwards under primary cleaning fans (Figure 16A). A lower cross-conveyor belt directs fruit toward the OTR conveyor. The cleaning fan system consists of two or three fans that draw in air as the fruit drops (Figure 16B). Because leaves are lighter than fruit, they are sucked into the air stream, chopped up, and exhausted toward the rear of the harvesters. A final cleaning fan is mounted at the end of the cross conveyor before the berries are transferred to the OTR to clean any remaining debris. The OTR system also has a cleaning system for MOG. This cleaning system consists of a powerful magnet (Figure 16C) that removes ferrous materials such as pieces of wire, clips, wrenches, screwdrivers, etc., which can damage pumps and bladders at the winery.
Quality concerns. Mechanical harvesters do not remove $100 \%$ of the berries from grapevines. Up to $5 \%$ of berries may be left behind, and this is an acceptable level. The goal is not to over pick but to leave rotten and raisined berries on the grapevine. As the mechanical harvester shakes the canopy, leaves are also removed. It is desirable for 70 to $80 \%$ of the leaf area to remain intact after harvest to help the plant amass additional carbohydrates and recover mobile nutrients from the leaves, both of which help grapevines regrow the following season.

Fruit temperature during harvest can affect must quality. Because a large mass of berries is picked and conveyed into a trailer (usually $6.7 \mathrm{t} / \mathrm{bin}$ ), the temperature of the loads do not change rapidly. The time in transit should not take longer than $6 \mathrm{hr}$ or the temperature of the load may increase and excessive oxidation may occur.

Growers must consider that the same harvester, or harvester settings, will not work optimally in all vineyards. Adjustments need to be made to optimize harvest in each vineyard. Only certain varieties are easily harvested mechanically. Some varieties, especially those with short peduncles, can be difficult to harvest with machines. For example, Bordelais cultivars, such as Merlot or Cabernet Sauvignon, are easily harvested by machines. Conversely, Sauvignon blanc, or certain clones of Pinot noir are more challenging. Likewise, certain clones of Chardonnay with short peduncles can only be harvested reliably by trunk-shaker harvesters.

\section{Significance}

The rising cost and decreasing availability of farm labor in California and other important winegrape growing regions has heightened interest in mechanization. Currently, machines are available to mechanize the most laborious cultural practices used for producing winegrapes, including pruning, canopy management, and harvest. Making the best use of these machines requires a holistic approach that considers the vineyard site characteristics, grapevine cultivar, trellising, and equipment available. Vineyard accessibility and uniformity is important, and fewer, more well-trained staff are needed to calibrate and operate machines effectively. Machine use may be limited to one or two laborious tasks, but the opportunity exists to integrate machines into most tasks in a way that optimizes grape yield and quality.

\section{References and Endnotes}

1. Kurtural SK, Beebe AE, Martínez-Lüscher J, Zhuang S, Lund KT, McGourty G and Bettiga LJ. 2019. Conversion to mechanical pruning in vineyards maintains fruit composition while reducing labor costs in 'Merlot' grape production. HortTechnology 29:128-139. 
2. Hobbs M, Herrero T, Klachky E and Cooper M. 2020. Leveraging pay and benefits as workforce retention strategies: Insights from a case study of Napa vineyard workers. Catalyst 4:33-38.

3. Beatty T, Hill AS, Martin P and Rutledge Z. 2020. COVID-19 and farm workers: Challenges facing California agriculture. In ARE Update 23:2-4. University of California Giannini Foundation of Agricultural Economics. https://s.giannini. ucop.edu/uploads/giannini_public/12/35/1235dbbd-cb7d42fa-b1a9-7ec40cd22ecb/v23n5_2.pdf.

4. Yu R and Kurtural SK. 2020. Proximal sensing of soil electrical conductivity provides a link to soil-plant water relationships and supports the identification of plant water status zones in vineyards. Front Plant Sci 11:244.

5. Pezzi F and Martelli R. 2015. Technical and economic evaluation of mechanical grape harvesting in flat and hill vineyards. Trans ASABE 58:297-303.

6. Terry DB and Kurtural SK. 2011. Achieving vine balance of Syrah with mechanical canopy management and regulated deficit irrigation. Am J Enol Vitic 62:426-437.

7. Hendrickson DA, Lerno LA, Hjelmeland AK, Ebeler SE, Heymann H, Hopfer H, Block KL, Brenneman CA and Oberholster A. 2016. Impact of mechanical harvesting and optical berry sorting on grape and wine composition. Am J Enol Vitic 67:385-397.

8. Geller JP and Kurtural SK. 2013. Mechanical canopy and crop-load management of Pinot gris in a warm climate. Am J Enol Vitic 64:65-73.

9. Yu R, Cook MG, Yacco RS, Watrelot AA, Gambetta G, Kennedy JA and Kurtural SK. 2016. Effects of leaf removal and applied water on flavonoid accumulation in grapevine (Vitis vinifera L. cv. Merlot) berry in a hot climate. J Agric Food Chem 64:8118-8127.

10. Cook MG, Zhang Y, Nelson CJ, Gambetta G, Kennedy JA and Kurtural SK. 2015. Anthocyanin composition of Merlot is ameliorated by light microclimate and irrigation in central California. Am J Enol Vitic 66:266-278.

11. Intrieri C, Poni S, Lia G and del Campo MG. 2001. Vine performance and leaf physiology of conventionally and minimally pruned Sangiovese grapevines. Vitis 40:123-130.

12. Morris JR. 2007. Development and commercialization of a complete vineyard mechanization system. HortTechnology 17:411-420.

13. Morris JR. 1999. Developing mechanized systems for producing, harvesting, and handling brambles, strawberries, and grapes. HortTechnology 9:22-31.

14. Morris JR and Cawthon DL. 1981. Yield and quality response of Concord grapes (Vitits labrusca L.) to mechanized vine pruning. Am J Enol Vitic 32:280-282.

15. Kurtural SK, Dervishian G and Wample RL. 2012. Mechanical canopy management reduces labor costs and maintains fruit composition in 'Cabernet Sauvignon' grape production. HortTechnology 22:509-516.

16. Herrero-Langreo A, Tisseyre B, Goutouly JP, Scholasch T and van Leeuwen C. 2013. Mapping grapevine (Vitis vinifera L.) water status during the season using carbon isotope ratio $\left(\delta^{13} \mathrm{C}\right)$ as ancillary data. Am J Enol Vitic 64:307-315.
17. Williams LE and Ayars JE. 2005. Grapevine water use and the crop coefficient are linear functions of the shaded area measured beneath the canopy. Agr Forest Meteorol 132:201-211.

18. Brillante L, Mathieu O, Bois B, van Leeuwen $C$ and Lévêque J. 2015. The use of soil electrical resistivity to monitor plant and soil water relationships in vineyards. Soil 1:273-286.

19. Brillante L, Martínez-Luscher J, Yu R, Plank CM, Sanchez L, Bates TL, Brenneman C, Oberholster A and Kurtural SK. 2017. Assessing spatial variability of grape skin flavonoids at the vineyard scale based on plant water status mapping. J Agric Food Chem 65:5255-5265.

20. Yu R, Brillante L, Martínez-Lüscher J and Kurtural SK. 2020. Spatial variability of soil and plant water status and their cascading effects on grapevine physiology are linked to berry and wine chemistry. Front Plant Sci 11:790.

21. Martínez-Lüscher J, Brillante L, Nelson CC, Al-Kereamy AM, Zhuang S and Kurtural SK. 2017. Precipitation before bud break and irrigation affect the response of grapevine 'Zinfandel' yields and berry skin phenolic composition to training systems. Sci Hortic 222:153-161.

22. Kurtural SK, Wessner LF and Dervishian G. 2013. Vegetative Compensation response of a procumbent grapevine (Vitis vinifera cv. Syrah) cultivar under mechanical canopy management. HortScience 48:576-583.

23. Wessner LF and Kurtural SK. 2013. Pruning systems and canopy management practice interact on the yield and fruit composition of Syrah. Am J Enol Vitic 64:134-138.

24. Martínez-Lüscher J, Brillante L and Kurtural SK. 2019. Flavonol profile is a reliable indicator to assess canopy architecture and the exposure of red wine grapes to solar radiation. Front Plant Sci 10:10.

25. Torres N, Yu R, Martínez-Lüscher J, Kostaki E and Kurtural SK. 2021. Application of fractions of crop evapotranspiration affects carbon partitioning of grapevine differently in a hot climate. Front Plant Sci 12:633600.

26. Pool RM, Pratt C and Hubbard HD. 1978. Structure of base buds in relation to yield of grapes. Am J Enol Vitic 29:36-41.

27. Kurtural SK, Stewart D and Sumner D. 2020. Sample Costs to Establish a Vineyard and to Produce Wine Grapes. Cabernet Sauvignon, North Coast Region, Napa County, Crush District 4. UC Cooperative Extension-Agricultural Issues Center, Davis, CA.

28. Intrieri C, Poni S, Lia G and del Campo MG. 2001. Vine performance and leaf physiology of conventionally and minimally pruned Sangiovese grapevines. Vitis 40:123-130.

29. de Toda FM and Sancha JC. 1999. Long-term effects of simulated mechanical pruning on Grenache vines under drought conditions. Am J Enol Vitic 50:87-90.

30. Nelson CC, Kennedy JA, Zhang Y and Kurtural SK. 2016. Applied water and rootstock affect productivity and anthocyanin composition of Zinfandel in central California. Am J Enol Vitic 67:18-28.

31. Tardaguila J, Petrie PR, Poni S, Diago MP and de Toda FM. 2008. Effects of mechanical thinning on yield and fruit composition of Tempranillo and Grenache grapes trained to a vertical shoot-positioned canopy. Am J Enol Vitic. 59:412-417. 
32. Dokoozlian N. 2013. The evolution of mechanized vineyard production systems in California. Acta Hortic 978:265-278.

33. Wilson PE, Archbold DD, Masabni JG and Kurtural SK. 2014. Cropload management of "Vidal blanc" improves primary bud cold hardiness and maintains berry composition in the lower midwestern United States. HortScience 49:874-880.

34. Gatti M, Civardi S, Bernizzoni F and Poni S. 2011. Long-term effects of mechanical winter pruning on growth, yield, and grape composition of Barbera grapevines. Am J Enol Vitic 62:199-206.

35. Brillante L, Martínez-Lüscher J and Kurtural SK. 2018. Applied water and mechanical canopy management affect berry and wine phenolic and aroma composition of grapevine (Vitis vinifera L., cv. Syrah) in central California. Sci Hortic 227:261-271.

36. Torres N, Martínez-Lüscher J, Porte E and Kurtural SK. 2020. Optimal ranges and thresholds of grape berry solar radiation for flavonoid biosynthesis in warm climates. Front Plant Sci 11:931.

37. Zhuang S, Fidelibus M, Kurtural SK, Lund K, Torres G, Stewart D and Sumner DA. 2019. Sample Costs to Establish a Vineyard and Produce Wine Grapes. Southern San Joaquin Valley, Fresno, Madera, Merced and Stanislaus Counties, Chardonnay Variety. UC Cooperative Extension-Agricultural Issues Center, Davis, CA.

38. Poni S, Casalini L, Bernizzoni F, Civardi S and Intrieri C. 2006. Effects of early defoliation on shoot photosynthesis, yield components, and grape composition. Am J Enol Vitic 57:397-407.

39. Fidelibus MW, Christensen LP, Katayama DG and Verdenal PT. 2005. Performance of Zinfandel and Primitivo grapevine selections in the central San Joaquin Valley, California. Am J Enol Vitic 56:284-286.

40. Palliotti A, Gatti M, and Poni S. 2011. Early leaf removal to improve vineyard efficiency: Gas exchange, source-to-sink balance, and reserve storage responses. Am J Enol Vitic 62:219-228.
41. Poni S, Bernizzoni F, Civardi S and Libelli N. 2009. Effects of pre-bloom leaf removal on growth of berry tissues and must composition in two red Vitis vinifera L. cultivars. Aust J Grape Wine Res 15:185-193.

42. Naor A, Gal Y and Bravdo B. 2002. Shoot and cluster thinning influence vegetative growth, fruit yield, and wine quality of 'Sauvignon blanc' grapevines. J Am Soc Hortic Sci 127:628-634.

43. Dami I, Ferree DC, Kurtural SK and Taylor BH. 2005. Influence of crop load on 'Chambourcin' yield, fruit quality, and winter hardiness under midwestern United States environmental conditions. Acta Hortic 689:203-208.

44. Kurtural SK, Dami IE, Taylor BH. 2006. Effects of pruning and cluster thinning on yield and fruit composition of 'Chambourcin' grapevines. HortTechnology 16:233-240.

45. Nuzzo V and Matthews MA. 2006. Response of fruit growth and ripening to crop level in dry-farmed Cabernet Sauvignon on four rootstocks. Am J Enol Vitic 57:314-324.

46. Dokoozlian NK and Kliewer WM. 1995. The light environment within grapevine canopies. I. Description and seasonal changes during fruit development. Am J Enol Vitic 46:209-218.

47. California Department of Food and Agriculture. 2013. California Grape Crush Report Final 2012. https://www. nass.usda.gov/Statistics_by_State/California/Publications/Specialty_and_Other_Releases/Grapes/Crush/ Final/2012/201203gcbtb00.pdf.

48. California Department of Food and Agriculture. 2014 California Grape Crush Report Final 2013. https://www. nass.usda.gov/Statistics_by_State/California/Publications/Specialty_and_Other_Releases/Grapes/Crush/ Final/2013/201303gcbtb00.pdf.

49. California Department of Food and Agriculture. 2015. California Grape Crush Report Final 2014. https://www. nass.usda.gov/Statistics_by_State/California/Publications/Specialty_and_Other_Releases/Grapes/Crush/ Final/2014/201403gcbtb00.pdf. 